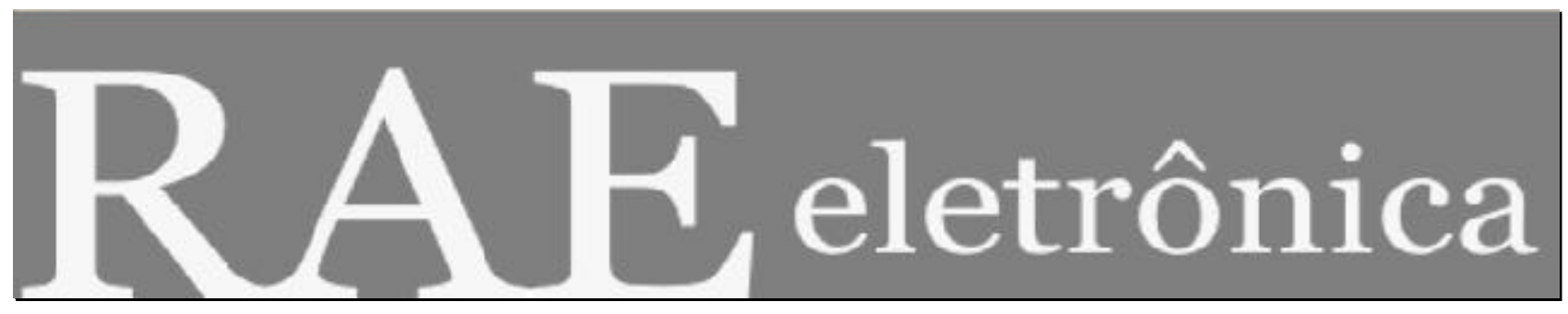

FÓRUM - GESTÃO NO BRASIL: ENFOCANDO PROCESSOS E RELACIONAMENTOS

\title{
MOVIMENTOS DE DESTERRITORIALIZAÇÃO E RETERRITORILIZAÇÃO NA TRANSFORMAÇÃO DAS ORGANIZAÇÕ ẼES
}

Por:

\section{Denise de Castro Pereira, PUC-MG}

Alexandre de Pádua Carrieri, UFMG

RAE-eletrônica, v. 4, n. 1, Art. 13, jan./jul. 2005

http://www.rae.com.br/eletronica/index.cfm?FuseAction=Artigo\&ID=2034\&Secao=FOR.GEST.B \&V olume $=4 \&$ Numero $=1 \&$ Ano $=2005$

CCopyright, 2005, RAE-eletrônica. Todos os direitos, inclusive de tradução, são reservados. É permitido citar parte de artigos sem autorização prévia desde que seja identificada a fonte. A reprodução total de artigos é proibida. Os artigos só devem ser usados para uso pessoal e nãocomercial. Em caso de dúvidas, consulte a redação: raeredacao@fgvsp.br.

A RAE-eletrônica é a revista on-line da FGV-EAESP, totalmente aberta e criada com o objetivo de agilizar a veiculação de trabalhos inéditos. Lançada em janeiro de 2002, com perfil acadêmico, é dedicada a professores, pesquisadores e estudantes. Para mais informações consulte o site www.rae.com.br/eletronica.

RAE-eletrônica

ISSN 1676-5648

(C2005 Fundação Getulio Vargas - Escola de Administração de Empresas de São Paulo.

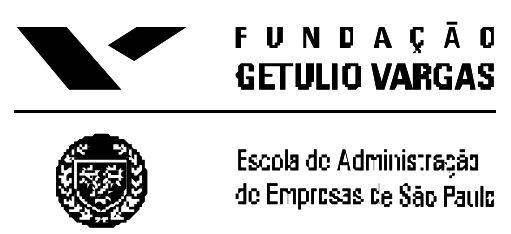


FÓRUM - GESTÃO NO BRASIL: ENFOCANDO PROCESSOS E RELACIONAMENTOS - MOVIMENTOS DE

DESTERRITORIALIZAÇÃO E RETERRITORILIZAÇÃO NA TRANSFORMAÇÃO DAS ORGANIZAÇÕES

Denise de Castro Pereira - Alexandre de Pádua Carrieri

\title{
RESUMO
}

O trabalho identifica as formas concretas e simbólicas de apropriação do espaço em uma empresa do setor de telecomunicações: a Telemig/Telemar-Minas. A disputa por espaços se liga ao sentido de territorialidade. Na medida em que os indivíduos defenderiam determinado espaço que lhes interessava, tais disputas envolveriam um amplo leque de dimensões como status e identidade, podendo refletir significações simbólicas que evidenciam relações de poder e dominação. Por meio de elementos da análise do discurso como instrumento metodológico básico para as análises sobre doze anos de atividades da empresa, observaram-se movimentos de desterritorialização e reterritorialização dos atores sociais envolvidos. Esses movimentos, somados às mudanças nas significações culturais, buscariam promover duas estratégias: a primeira, provocar um desenraizamento real e simbólico dos espaços; a segunda, tentar fazer com que a organização, por sua vez, apareça como um novo espaço de trabalho.

\section{PALAVRAS-CHAVE}

Espaços simbólicos, desterritorialização, reterritorialização.

\begin{abstract}
The work focuses the concrete and symbolic forms of appropriation of space in a company of the telecommunications sector: Telemig/Telemar-Minas. The dispute for spaces is closely connected to the sense of territoriality. As the individuals defend certain spaces that could interest them, these disputes involve a wide scope of dimensions, such as status, and identity. They possibly reflect symbolic significances in which relationships of power and dominance could be felt. Elements of the discourse analysis (DA) were employed as methodological instruments for the analyses of twelve years of activities of the company; the data was collected by interviews and study of countless documents written texts. The movements of unterritorialization and reterritorilization of the social actors' involved were reviewed. Those movements, added to the changes in the cultural significances, aim to promote two strategies - first, to provoke a real and symbolic uprooting of the spaces; second, to build a new workspace in the organization.
\end{abstract}

\section{KEYWORDS}

Symbolic spaces, unterritorialization, reterritorilization. 
FÓRUM - GESTÃO NO BRASIL: ENFOCANDO PROCESSOS E RELACIONAMENTOS - MOVIMENTOS DE

DESTERRITORIALIZAÇÃO E RETERRITORILIZAÇÃO NA TRANSFORMAÇÃO DAS ORGANIZAÇÕES

Denise de Castro Pereira - Alexandre de Pádua Carrieri

\section{INTRODUÇÃO}

Este trabalho tem como objetivo refletir sobre o tema dos espaços simbólicos e físicos, representados pelo território, nas organizações. $O$ estudo utiliza, empiricamente, uma pesquisa sobre as transformações das significações culturais em uma empresa do setor de telecomunicações ao longo dos anos 1990 a 2002 - trata-se da Telemig, posteriormente, Telemar-Minas. A pesquisa original oportunizou a apreensão das formas concretas e simbólicas de apropriação e reapropriação dos espaços pelos grupos e indivíduos naquela empresa. Busca-se, também, trazer contribuições para os estudos de gestão no Brasil, evidenciando o enfoque dos espaços simbólicos nos relacionamentos e processos organizacionais que advêm de uma construção sócio-histórica.

Para Santos (1987), o espaço pode ser compreendido como o conjunto de formas representativas de relações, ou mesmo uma estrutura representada por relações sociais que se manifestariam por meio de processos e funções. Nesse sentido, o espaço organizacional pode ser compreendido como a instância onde se articulam os seguintes elementos: os homens, as tecnologias e a estrutura, cuja relação constitui um sistema a partir das dimensões econômicas, sociais e culturais. Nas organizações, a disputa por espaços se liga ao sentido de territorialidade, entendida aqui como conjunto de ações, comportamentos de indivíduos ou grupos que tendem a afetar, influenciar ou controlar pessoas, fenômenos ou relações, combinando representações sociais e práticas espaciais, construindo suas bricolagens. A territorialidade se caracteriza como fenômeno de origem psicológica, constituindo dimensões sociais e políticas, pois se projeta como movimento que afeta as percepções do sujeito em relação à sua posição e aos papéis no interior da organização, considerada como território de ação social (Guattari, 1993; Raffestin, 1993; Haesbaert, 1997). Esses autores discutem o conceito de território vinculado a um processo contínuo de desterritorialização e reterritorialização. A desterritorialização compreende os mecanismos que separam o território das suas "raízes" sociais e culturais (Pagès et al., 1993), enquanto a reterritorialização vem a ser a criação de novos vínculos em substituição aos perdidos.

Nos estudos organizacionais o tema sobre o espaço simbólico, segundo Alcadipani e Almeida (2001), não aparece constantemente, todavia o tema do espaço físico, ainda que tratado, aparece como um elemento neutro ou secundário na gestão organizacional. Clegg, Kornberg e Dobers (2003) realçaram a ausência do tema "espaço" no campo administrativo do primeiro mundo. Mac-Allister (2003) registrou esSa ausência nos estudos brasileiros, e em uma releitura crítica dos recentes trabalhos aqui produzidos evidencia que $\mathrm{o}$ espaço é sistematicamente ignorado e, eventualmente, abordado por meio de conceitos correlatos, por vezes imprecisos, inclinados a reduzi- lo à questão de localização ou ao espaço-físico, dotado, a princípio, de sua dimensão econômica.

Este artigo sistematiza, numa prime ira seção, elementos conceituais como espaço e territorialidade. Em seguida aborda o percurso metodológico realizado na pesquisa de campo, para depois proceder à análise do movimento de desterritorialização e reterritorilização na transformação organizacio nal em uma empresa do setor de telecomunicações. Nas considerações finais, busca sintetizar o percurso feito pela pesquisa e destacar suas principais contribuições e desafios. 


\section{FÓRUM - GESTÃO NO BRASIL: ENFOCANDO PROCESSOS E RELACIONAMENTOS - MOVIMENTOS DE DESTERRITORIALIZAÇÃO E RETERRITORILIZAÇÃO NA TRANSFORMAÇÃO DAS ORGANIZAÇÕES Denise de Castro Pereira - Alexandre de Pádua Carrieri O ESPAÇO, O TERRITÓRIO E OS ESTUDOS ORGANIZACIONAIS}

As referências ao estudo do território e dos processos de territorialização, desterritorialização e reterritorialização nos remetem a campos diversificados como a geografia humana, a psicologia, a psicanálise, a sociologia e as teorias de organizações. A base, no entanto, encontra-se na dimensão humana em relação à construção no espaço social. Segundo Buttimer (1986), a articulação original de espaço social é encontrada em Durkheim, na década de 1890, como parte de suas formulações a respeito da diferenciação social. O território enche o espaço com conteúdos particulares, relacionados a construções históricas entre pessoas, organizações e Estado. A territorialidade, segundo Corrêa (1996), refere-se ao conjunto de práticas e suas expressões materiais e simbólicas, que garantiriam uma apropriação e uma permanência em um dado espaço por determinados grupos sociais, organizacionais. $\mathrm{O}$ território agora pode ser visto não somente pela perspectiva do domínio físico, mas também de uma apropriação que incorpora a dimensão simbólica e, pode-se dizer, identitária, afetiva. Em um sentido contrário, o movimento denominado desterritorialização viria para esvaziar o território (e os espaços ocupados) de seu conteúdo relacional e particular, que promoveria uma identificação entre os indivíduos e as organizações. Assim a desterritorialização pode ser vista como uma estratégia dos grupos dominantes para conter, restringir e até excluir pessoas, isto é, como um movimento de (re)apropriação do território, dos espaços físicos e simbólicos (Guattari, 1993). Pode ainda ser vista como um processo de "deformação" da relação do indivíduo e de grupos com a organização (Pagès et al., 1987), como um movimento de rompimento da história organizacional, que, para ser compreendida, necessita de uma referência territorial, pois se atualizaria sempre no espaço da organização.

Para Harvey (1992), a apropriação do espaço traduz a maneira como ele é ocupado por objetos, atividades, indivíduos e grupos. No caso particular de uma organização, o domínio sobre o território refletiria como os grupos dominantes se apropriariam da produção dos espaços simbólicos e físicos, a fim de poderem exercer um maior grau de controle sobre os indivíduos. Nesse sentido, uma possível transformação das significações organizacionais, processada pela tentativa de substituição de uma visão compartilhada, pode ser entendida como um processo de desterritorialização. Também as alterações no controle da propriedade, a troca de tecnologias, sistemas, processos, rotinas, papéis, práticas, estilos de gestão, a substituição de dirigentes ou a mudança de locais de trabalho podem ser vistas como processos de desterritorialização, que trazem em si novos processos de reterritorialização nos quais há buscas contínuas de outros significados em substituição dos perdidos.

As organizações, como territórios, possibilitam a construção de significações culturais e de identidades atribuídas pelos grupos organizacionais como forma de controle simbólico sobre o espaço onde trabalham. O uso cotidiano dos espaços simbólico e físico pertencentes a cada grupo organizacional seria um exemplo claro das transformações nas significações culturais, da transfiguração das relações de dominação e de submissão existentes em quaisquer organizações. Na verdade, cada grupo transformaria em seu o espaço organizacional pensado pela alta administração, por meio de bricolagens simbólicas para o seu uso. No cotidiano das organizações, cada grupo desenvolveria sua produção de significados pela colagem de diferentes discursos, caracterizando um instrumento metafórico que poderia ilustrar processos sociais subjacentes aos vários significados simbólicos, no caso do estudo, acoplados à noção de espaço (Certeau, 1994). É interessante destacar que no discurso oficial das organizações existe, para dominar e manter uma suposta união das pessoas dentro da organização e a integração dos grupos, uma gama de símbolos reutilizados especificamente pelos diversos grupos, como o macacão para o pessoal do chão de 
FÓRUM - GESTÃO NO BRASIL: ENFOCANDO PROCESSOS E RELACIONAMENTOS - MOVIMENTOS DE DESTERRITORIALIZAÇÃO E RETERRITORILIZAÇÃO NA TRANSFORMAÇÃO DAS ORGANIZAÇÕES Denise de Castro Pereira - Alexandre de Pádua Carrieri

fábrica, terno e gravata para os gerentes, e uma infinidade de exemplos que um estudo organizacional poderia evidenciar.

No uso dos espaços também estariam sendo criadas, ou recriadas, formas de se restabelecer a autoridade ameaçada pelo processo da construção de bricolagens. O restabelecimento do poder dos símbolos, segundo afirma Bourdieu (1989), obriga o sujeito a romper e suspender suas representações individuais do mundo, retirando do sujeito o poder da criação simbólica. Dessa forma, o indivíduo aceita os usos simbólicos, como do espaço, incorporand o-os como coisas suas, comuns à sua vida, e os traz para seu cotidiano, por exemplo, na organização, na família e na questão sexual. Para Certeau (1994), no entanto, os indivíduos aceitariam todas ou, pelo menos, uma grande parte das referências simbólicas criadas, assim concordariam com o que lhes é imposto e se colocariam aptos a viver em sociedade. Ao aceitarem esse conjunto de símbolos, os sujeitos acabam por trazê-los para a sua individualidade, criando bricolagens simbólicas. As bricolagens seriam observáveis no cotidiano das pessoas, pois é no dia-a-dia que interagem os grupos e se dá a ocupação dos espaços concretos e simbólicos.

No campo dos estudos organizacionais brasileiros, Fernandes, Fonseca e Machado-da-Silva (2000), Spink (2001), Vieira e Vieira (2002), trabalham conceitos relacionados também ao tema espaço. Esses autores buscam relacionar o espaço local e o global trazendo sempre, ou quase sempre, o aspecto econômico como dimensão mais importante, esvaziando a dimensão social, que, segundo Mac-Allister (2001), é indissociável da dimensão espacial. Nesse esvaziamento do social - e como consequiência do relacional -, perdem-se componentes da dimensão simbólica, esvazia-se o território, e o espaço se reduz, passando a ser, em essência, uma objetivação do espaço-físico onde acontece a produção econômica.

Rodrigues (1997) estuda as formas de ocupação do espaço e as suas implicações para a gerência, destacando a importância do espaço simbólico no contexto organizacional. O espaço simbólico é ambíguo e relacional, e depende do consenso social em situações de interação. Permite revelar traços culturais, identitários e outros aspectos importantes no contexto das organizações. Segundo esta autora, as formas simbólicas e concretas de apropriação do espaço nas organizações variam muito e são resultantes de intensa negociação. Incorporando o pressuposto de que a disputa por espaços se associa ao sentido de territorialidade, o processo organizacional retrata como indivíduos e grupos se relacionam, compartilham interesses ou competem. Na medida em que os indivíduos defenderiam determinados espaços que lhes interessam, tais disputas envolveriam um amplo leque de dimensões, como status e identidade, podendo refletir significações simbólicas em que se dariam as relações de poder e dominação.

Corrêa (1996) afirma que uma das perspectivas que contempla m o espaço e o território das empresas, pelo menos no âmbito das grandes corporações, seria abordar o tema da organização e seu território produtivo, como, por exemplo, a Sadia e seu mercado de produtores de aves e suínos, ou a Itambé e seu mercado de produtores de leite. Além disso, esse autor afirma que se pode estudar a desterritorialização como uma proposta programada e executada em nome da suposta maior eficiência econômica e maiores ganhos efetivos, por meio de questões como: Qual seria o alcance territorial dessas empresas? Quais as formas de gestão impostas para seu território produtivo? O que foi excluído no processo de aumento da eficiência econômica? No caso da empresa de telecomunicações aqui apresentada, a pesquisa não estava particularmente interessada em saber qual era o seu mercado produtivo, mas qual foi o movimento de transformação organizacional da Telemig/Telemar e quais as redefinições espaciais e territoriais introduzidas na organização e nas práticas de gestão que evidenciariam processos de mediação entre o individuo e a organização, como, por exemplo, o processo de desterritorialização. 
FÓRUM - GESTÃO NO BRASIL: ENFOCANDO PROCESSOS E RELACIONAMENTOS - MOVIMENTOS DE

DESTERRITORIALIZAÇÃO E RETERRITORILIZAÇÃO NA TRANSFORMAÇÃO DAS ORGANIZAÇÕES

Denise de Castro Pereira - Alexandre de Pádua Carrieri

Diante dessas questões, com base em textos orais e escritos, foi possível orientar a análise no sentido de captar representações interiorizadas pelos atores organizacionais e resgatar a trajetória da transformação territorial ocorrida na Telemig, hoje Telemar-Minas. Sabendo-se que é na indissociável relação entre a dimensão social e a dimensão espacial, bem como entre essas dimensões e a dimensão temporal (Mac-Allister, 2001), que se constituem os processos de apropriação do espaço e do território, buscou-se adotar como focos para análise, neste trabalho, os seguintes elementos: a história da organização - uma construção temporal de decisões e ações; suas diferentes identidades; o poder refletido em papéis e posições estabelecidos na estrutura organizacional - reconstruções de espaços simbólicos; a reconstrução dos espaços físicos e as novas representações que estes embutiam.

\section{PERCURSO METODOLÓGICO: AS NARRATIVAS E A OCUPAÇÃO DOS ESPAÇOS}

$\mathrm{Na}$ abordagem empírica dessa pesquisa, procedeurse a um estudo de caso em uma empresa do setor de telecomunicações em Minas Gerais: Telemig/Telemar-Minas. Focalizou-se a história dessa organização durante toda a década de 1990 e sua transformação de empresa pública em filial de uma holding privada. Para Mumby e Clair (1997), as pesquisas sobre as histórias organizacionais ganham cada vez mais ênfase nos estudos organizacionais. Esses autores apontam o estudo das narrativas como fontes importantes para o conhecimento sobre as organizações. Pode-se, então, estudar somente as narrativas e observar como elas percorrem os diferentes grupos e atores organizacionais.

A adoção da análise do discurso (AD) possibilitou examinar como as significações constituintes dos valores, das identidades, são articuladas no discurso de quem tem poder de decisão e repassadas para a organização como um todo. Os discursos desempenham um papel ativo na passagem do subjetivo (as significações dadas pelos atores organizacionais aos novos processos e práticas gerenciais e à nova identidade da organização) para o objetivo (a linguagem escrita e falada) (Faria e Linhares, 1998). Por esse motivo, neste trabalho, a $\mathrm{AD}$ foi considerada uma ferramenta de investigação e busca de compreensão das significações culturais, espaciais e identitárias na organização.

Deve-se ainda ressaltar que as narrativas aqui analisadas foram produzidas na medida em que a pesquisa procurou resgatar um processo histórico que remonta ao começo da década de 1990, com base em informações coletadas a posteriori, em 2000 a 2002. As informações foram obtidas por meio de aproximadamente 100 entrevistas em profundidade com funcionários, gerentes e representantes da alta administração. Para a melhor compreensão dessa história, analisaram-se documentos, especificamente os Relatórios Anuais e jornais da empresa (DDdicas e Jornal Telemar) e do sindicato (O Bode Berra e O Bodim), produzidos no período em estudo.

As narrativas evidenciadas pelos entrevistados e em documentos revelaram a articulação entre as transformações da organização e a ocupação e desocupação dos espaços, ou melhor, os movimentos de desterritorialização e reterritorialização. Coube aos pesquisadores buscar identificar as práticas descritas nos discursos organizacionais, pois era por meio delas que ocorria a configuração das velhas e novas identidades, dos desejos, das explicações, das justificativas e racionalizações existentes na formação organizacional em que os indivíduos estavam inseridos. Para isso, realizourse a seleção temática, a construção e desconstrução de personagens, o que era explícito e implícito, e o que era 
FÓRUM - GESTÃO NO BRASIL: ENFOCANDO PROCESSOS E RELACIONAMENTOS - MOVIMENTOS DE

DESTERRITORIALIZAÇÃO E RETERRITORILIZAÇÃO NA TRANSFORMAÇÃO DAS ORGANIZAÇÕES

Denise de Castro Pereira - Alexandre de Pádua Carrieri

silenciado nos fragmentos discursivos dos atores organizacionais e dos documentos. Podendo-se, então, traçar alguns percursos semânticos (Faria, 2001) sobre os espaços simbólicos evidenciados na análise deste trabalho, mais precisamente nas três fases em que a análise foi construída: o percurso semântico sobre o começo da desterritorialização; o percurso do aprofundando da desterritorialização para efetivar a privatização da empresa; e o percurso semântico de uma reterritorialização que estaria sendo elaborada pela alta administração da empresa para reconstruir um "novo" espaço organizacional.

\section{PREPARANDO O TERRENO: O COMEÇO DA DESTERRITORIALIZAÇÃO}

Ao se analisar os fragmentos discursivos coletados, pode se observar um conjunto de mudanças que impulsionaram a transformação das sgnificações das identidades e significações da Telemig, na perspectiva de controlar e homogeneizar as visões de mundo na organização. Ocorreu um movimento de transformação que começou muito lentamente e, em seu cerne, preparava a empresa para uma abertura do setor e sua possível privatização. Quando essas perspectivas se tornaram realidade, as mudanças aconteceram mais rapidamente, visando, sobretudo, a aprofundar as novas visões gerenciais implementadas desde o começo dos anos 1990.

A diretoria buscaria implementar o que foi denominado por ela "modernizações em toda a empresa", seja no plano concreto - operacional -, seja, principalmente, no plano abstrato - cultural e simbólico. No plano concreto, a diretoria implantou os programas de qualidade e reengenharia, considerados por muitos empregados como os precursores da transformação da identidade da organização, ou seja, de empresa centrada em si mesma e no uso da tecnologia, passou a empresa aberta, ofertando serviços de telecomunicações.

A própria empresa, a Telemig, nos discursos da alta administração, era vista como uma firma de engenharia na qual predominava a visão tecnicista, nunca ressaltando estar voltada para a satisfação do cliente. Deve-se destacar que aos poucos começa a se delinear uma mudança simbólica importante. A organização, que até então tinha como alicerce de seu conhecimento a engenharia, tendo os engenheiros, como grupo, um determinado poder, volta-se agora para o que se define como cliente, objeto de estudo da gestão. A organização deveria deixar de ser uma empresa de engenharia, e, portanto, os engenheiros deveriam deixar de ser "donos" de um conhecimento acumulado pela história da empresa, oportunizando aos administradores um novo alinhamento com as estruturas de decisão da organização.

Outro aspecto importante e também uma das manifestações do começo da desterritorialização, aprofundada pela diretoria, foi o deslocamento do foco de usuário para cliente. Para a alta administração, havia a intenção de abrir a empresa para o mercado, personificado pelos clientes. Buscou-se fazer com que empresa, pelo menos a alta administração, saísse de seu território e fosse criar novos vínculos com o mundo real, competitivo e privado. A proposição inicial era a da implementação de estratégias que modernizassem a empresa, principalmente pelos processos gerenciais de atendimento ao cliente, justificados como necessários, em função das alterações no mundo externo à organização. A modernização traz sua nova identidade: "prestadora de serviços". 
FÓRUM - GESTÃO NO BRASIL: ENFOCANDO PROCESSOS E RELACIONAMENTOS - MOVIMENTOS DE DESTERRITORIALIZAÇÃO E RETERRITORILIZAÇÃO NA TRANSFORMAÇÃO DAS ORGANIZAÇÕES Denise de Castro Pereira - Alexandre de Pádua Carrieri

Uma das bases de sustentação das ações dessa diretoria era o corpo gerencial, mais precisamente o Conselho de Gerentes de Departamento - Conger. Ao Conger se atribuía o poder de responsabilizar-se pelas decisões a partir das quais os processos seriam mapeados e redesenhados, podendo levar à transformação e até ao desaparecimento de departamentos, divisões e seções, enfim, de cargos ocupados pelos gerentes. É interessante destacar que o Conger promovia uma demarcação territorial (Fischer, 1994). As pessoas que pertenciam ao conselho eram as pessoas "próximas" da diretoria, aliadas da alta administração. Demarcava-se, com a participação no conselho, o território de ação dos indivíduos na organização, que servia, metaforicamente, de "camada impermeabilizante", pois isolava a organização das más diretorias e, muitas vezes, como se viu, podia até mesmo tomar decisões como se fosse a própria alta administração. Além disso, para alguns participantes, ninguém é mais importante que o Conger, evocando-se um forte espírito de corporativismo.

\section{UTILIZANDO-SE DO TERRENO ARADO: APROFUNDAR A DESTERRITORIALIZAÇÃO PARA PRIVATIZAR}

Por parte da nova diretoria que assumiu a Telemig, foram elaboradas e colocadas em prática várias estratégias, tanto no plano concreto como no plano das significações simbólicas da organização. Se nos fragmentos discursivos da diretoria passada, observados no tópico anterior, pode-se evidenciar a proposta de formação de uma nova visão gerencial com valores voltados para a satisfação dos clientes, do mercado, para o aumento da rentabilidade da empresa e para a nova identidade de prestadora de serviços, com a intenção de se implementar uma determinada visão de mundo por toda a Telemig, para essa nova diretoria - presidente e membros - o momento era de usar desse "terreno arado" e buscar aprofundar e institucionalizar aa mudanças de valores; contudo, era preciso fazer ajustes, como reforçar alguns aspectos considerados importantes e modificar outros, para definitivamente transformar a Telemig em uma empresa de negócios de telecomunicações.

Nessa segunda fase, pode-se ver mais claramente que a centralização espacial começa a acontecer. As decisões são temporariamente centralizadas em Belo Horizonte, sede da matriz. Muitas pessoas são trazidas do interior para trabalhar e morar na capital mineira. Ocupam-se em minar os centros de poder das regionais - funcionando como centros de poder externo à matriz, com fortes territórios de influência sobre determinadas regiões mineiras - e dos gerentes, do Conger, que servia de camada impermeabilizante das ações das diretorias. Ainda nessa fase, pode-se ver, mais claramente, a arena simbólica (Rodrigues e Collinson, 1995) em que se transformou a Telemig. De um lado, um número significativo dos atores organizacionais aos poucos parece perder suas próprias significações culturais, para cada vez mais incorporar as da alta administração. Os temas e personagens referidos revelam essa perda, pois estão em sua maioria nos discursos da diretoria. Do outro lado, há pessoas nesses grupos que buscam resistir e manter ainda determinada visão da empresa, de sua história enquanto Telemig. É nessa fase que o movimento de desterritorialização se aprofunda; a empresa sofre mudanças, principalmente no interior mineiro, onde os feudos, poderes paralelos, foram esvaziados e seu pessoal mais importante, trazido para perto da administração central. É interessante destacar o papel de mediação que a diretoria desempenha, promovendo funcionários de nível técnico a gerentes, e viceversa; muitos gerentes poderosos voltaram a ser técnicos. Buscou-se esvaziar os espaços conquistados 
FÓRUM - GESTÃO NO BRASIL: ENFOCANDO PROCESSOS E RELACIONAMENTOS - MOVIMENTOS DE DESTERRITORIALIZAÇÃO E RETERRITORILIZAÇÃO NA TRANSFORMAÇÃO DAS ORGANIZAÇÕES Denise de Castro Pereira - Alexandre de Pádua Carrieri

por anos de história, de relacionamentos interpessoais de longos anos de Telemig, preparando-se a mudança de organização pública para empresa privada.

Um dos principais enfoques dados nesse processo de desterritorialização foi acabar, ou ao menos minimizar, as velhas estruturas de poder que não permitiam a institucionalização da visão de nova diretoria. Ao executarem o que, internamente, denominourse reestruturação, propunha-se uma centralização do poder em Belo Horizonte e a extinção das mini-Telemigs, ou vice-reinos, ou ainda feudos que eram ocupados pelos gerentes nas áreas do interior, como se retrata nos depoimentos a seguir:

[...] era preciso estar mexendo fortemente no interior, nos antigos distritos que eram miniTelemigs...que eram Telemigs... eles usam exatamente a questão dos feudos do interior. (diretor 1)

Segundo é que existe lá o que eu chamava de os vice-reis, tinha Telemig aqui e tinha as regiões [...], eram sete,... eram sete, que a formação assim, o gerente era responsável por tudo (...) era quase que sete empresas. E então, o que que aconteceu? Criava aquelas ligações, e presidentes que eram da casa tinham mais simpatia por um por outro e tal. (diretor 3)

Antes a empresa era estruturada em regiões de operação, ou seja, reinados, o gerente de região, ele era vitalício, ele sabia da vida de cada funcionário e punha, ele mandava, ele mandava mesmo, tinha o poder muito forte, às vezes maior que o prefeito em determinados lugares, ninguém mexia, eram intocáveis os gerentes de região. (diretor 4)

Quando se mexeu nas regiões de operação, imagina o vespeiro que era aquilo... entendeu? Mas um vespeiro, o negócio foi forte mesmo, e brigas, de nêgo ir ao ministro tentar tirar o presidente e... quebrou a cara. (ex-assessor da diretoria)

Distritos, mini-Telemigs, miniaturas da Telemig e seus diretores locais. Vice-reis e seus vice-reinos, governadores de um estado ou província de um reino. Feudos, propriedade territorial de um senhor feudal que devia prestar obediência a um rei. Outra imagem adotada em depoimentos foi a do vespeiro. Vespeiro, moradia de vespas, de insetos que possuem uma rainha e vivem em colônias, também possuem intrínsecas ligações para poderem sobreviver, têm ferrão, portanto picam, e sua picada pode doer muito. Esses são alguns dos vocábulos metafóricos usados para caracterizar a estrutura da Telemig quanto ao poder, as decisões e o envolvimento com os poderes locais/regionais. $\mathrm{O}$ uso das denominações feudos e vice-reinos traz, implicitamente, a visão de antigüidade, de algo não moderno e não condizente com a fim do século XX. Para que essa nova diretoria implementasse as mudanças desejadas, não poderiam existir miniaturas da Telemig. $O$ poder deveria estar centralizado e não dividido, de maneira semelhante ao fortalecimento dos reinos e o fim dos feudos. Era preciso tornar a empresa mais e mais rentável para quem quer que fosse comprá-la. 
FÓRUM - GESTÃO NO BRASIL: ENFOCANDO PROCESSOS E RELACIONAMENTOS - MOVIMENTOS DE

DESTERRITORIALIZAÇÃO E RETERRITORILIZAÇÃO NA TRANSFORMAÇÃO DAS ORGANIZAÇÕES

Denise de Castro Pereira - Alexandre de Pádua Carrieri

Em decorrência disso, uma outra estratégia foi acabar com o Conselho de Gerentes - o Conger. Para essa diretoria, o Conger era visto como um obstáculo que "se interpunha entre a presidência e a diretoria e a empresa" (ex-assessor da diretoria).

Considerava-se que, para a nova diretoria agir e executar o que era elaborado pelo Ministério de Comunicação, não poderia haver a barreira que se interpunha entre quem mandava e a empresa. $\mathrm{O}$ discurso organizado foi de que o Conger impossibilitava a empresa de fazer uma gestão totalmente voltada para a satisfação dos clientes; o conselho não deixava que a empresa servisse ao cliente, pois se apresentava como uma instituição encerrada no território da nova diretoria, e nada melhor para provocar uma ruptura do que destruir essa instituição. Desfazendo-se do Conger se poderia tentar institucionalizar nova cultura integradora, novos conhecimentos e novos papéis a desempenhar, e em troca adquirir lealdade, integração e identificação. Para minar a existência de possíveis resistências, organizoutse um discurso no qual se igualavam os gerentes que não desejavam tais mudanças aos generais.

Segundo alguns gerentes, rompeurse com a estrutura de feudos que formava a Telemig e centralizou-se o poder em Belo Horizonte, para poder preparar a empresa para a privatização. O "fim" dos feudos e a centralização do poder na diretoria trazem a desativação das estruturas hierárquicas que sustentavam esses feudos, os funcionários eram chamados a trabalhar em Belo Horizonte, separava-se o individuo de sua história, desenraizavam-se as pessoas de seus lugares, de suas cidades, tentando-se substituir suas referências originais por outras, conforme os novos interesses da empresa. Observou-se, então, o forte processo de desterritorialização dos indivíduos e do próprio espaço produtivo da Telemig.

A nova diretoria decide, para tentar desmistificar de uma vez a área técnica, área em que os gerentes de departamento construíram suas histórias, seus poderes, seus conhecimentos, não promover mais reuniões desses gerentes, não os consultar mais, e, como já foi dito, nomeia outros gerentes para ocupar os departamentos vinculados às novas áreas de negócios. Esse é, segundo os gerentes, mais um paradigma rompido com a reestruturação, ou seja, o velho tema da empresa voltada ainda para a engenharia. A reestruturação é vista como um processo que se realiza para, finalmente, mudar esse poder baseado no saber técnico. Na nova estrutura, as áreas de negócios criadas é que determinariam o que é mais importante, apontando que o conhecimento principal será aquele relacionado diretamente ao mercado - serviços, vendas, marketing, custos - futuro, único foco de uma Telemig privatizada.

Para marcar essa transformação, muda-se também o logotipo da empresa. Um símbolo de sua própria imagem/identidade. A Telemig passou a ter um logotipo composto por elementos mais simples, de fácil memorização, provocando a impressão de algo mais leve e moderno. A diretoria queria que esse logotipo fosse assimilado como a nova identidade visual da empresa, mas também que essa imagem fosse associada com a própria diretoria.

\section{COLHENDO OS PRODUTOS: A FILIAL E A RETERRITORIALIZAÇÃO?}

Nessa fase, observa-se uma grande centralização; afinal 16 empresas de telefonia configuram-se como Telemar, com matriz no Rio de Janeiro. A empresa espalha-se por grande parte do território nacional, 
FÓRUM - GESTÃO NO BRASIL: ENFOCANDO PROCESSOS E RELACIONAMENTOS - MOVIMENTOS DE

DESTERRITORIALIZAÇÃO E RETERRITORILIZAÇÃO NA TRANSFORMAÇÃO DAS ORGANIZAÇÕES Denise de Castro Pereira - Alexandre de Pádua Carrieri

cada ex-empresa pública se transforma em produtora de determinado produto, mão-de-obra, conhecimento. Reduzem-se a verdadeiras filiais.

Por ser filial de uma empresa privada, onde o que realmente interessa são os ganhos dos acionistas, observa-se uma constante mudança nos espaços físicos e simbólicos. Poderia demitir e contratar como muitas, com maior facilidade, o que levou a rupturas na identificação entre empresa e funcionários. Podem-se realocar pessoas para vários lugares, em todo o Brasil; caso não quisessem aceitar, seriam demitidas. O movimento de desterritorialização, de separação das pessoas de suas raízes sociais e culturais, deveria ser continuado para se garantirem dividendos aos acionistas. A união de dezesseis em uma só empresa opera uma grande centralização das decisões e uma forte homogeneização, padronização funcional, no sentido de todas as dezesseis possuírem a mesma cara, o mesmo logotipo, o mesmo uniforme, e de falarem a mesma linguagem técnica. Particularmente a agora filial TelemarMinas, além dessa padronização, pode ver seu espaço físico sendo continuadamente diminuído, enxugado, extinguindo-se alguns setores, criando-se outros, alocando-se e realocando-se pessoas em um espaço físico redesenhado, cada vez menor, onde todos se vigiam, onde até mesmo o gerente é controlado pelos seus funcionários.

Para a Telemig, agora Telemar-Minas, a mudança de nome se configurou uma perda de identidade, um movimento de desterritorialização de todos os seus funcionários, inclusive de seus empregados aposentados, que viram na mudança de nome uma perda de grande parte de sua vida. A mudança da marca Telemig foi organizada como um verdadeiro ritual de passagem, com depoimentos do pessoal da empresa envolvido diretamente com a mudança e de pessoas que assistiram ao pronunciamento do presidente da holding. As mudanças começavam a ocorrer cada vez em maior número, mais rápida e agressivamente. A diretoria da Telemar-Minas ampliava a arena do confronto simbólico que acontecia na empresa, para a ocupação dos espaços. Essas mudanças, concretas e visualmente palpáveis, tinham a finalidade de mostrar que a empresa mudaria muito, a realidade agora era outra. Para um diretor regional (outrora presidente) da ex-Telemig, o tempo de casa médio das pessoas era ainda alto, mais ou menos quinze anos, e somente por um "choque" é que muitas delas iriam perceber que as coisas estavam mudando.

Um exemplo da nova arena ou desse choque simbólico foi a mudança que atingiu o espaço de instalação da antiga sede, agora transformada em regional. No caso, o majestoso prédio, onde alguns andares foram alugados para terceiros, teve seus espaços internamente reestruturados. Surgiram portas de blindex e cartões magnéticos para abri-las; além disso, os espaços internos perderam divisórias para que todos vissem e controlassem a todos, para que inclusive as pessoas que viessem de fora pudessem também ver quem estava trabalhando ou não. A mudança de ocupação do espaço no prédio principal foi muito intensa, refletindo a redução do tamanho e da complexidade organizacional no subsistema regional. Mudaram-se andares inteiros. Refazendo-se o espaço de ocupação da empresa, diminuindo-o, na realidade a diretoria mostrava que a empresa estava encolhendo de fato e não somente mudando, como fora mencionado em fragmentos discursivos anteriores. Era uma efetiva desterritorialização das pessoas da empresa.

As formas concretas e simbólicas de apropriação do espaço variariam e resultariam de intensas disputas e negociações, reconstruindo e reproduzindo sentidos de territorialidades, podendo refletir renovadas significações simbólicas atinentes às relações de poder e dominação. Desse modo, a mudança espacial realizada pela alta administração da empresa tinha o sentido de proporcionar a desterritorialização. Quando foram internamente mudados setores funcionais; quando se alugou o espaço do prédio para outras empresas; quando se reduziu a quantidade de andares ocupados pela Telemar-Minas, 
FÓRUM - GESTÃO NO BRASIL: ENFOCANDO PROCESSOS E RELACIONAMENTOS - MOVIMENTOS DE

DESTERRITORIALIZAÇÃO E RETERRITORILIZAÇÃO NA TRANSFORMAÇÃO DAS ORGANIZAÇÕES

Denise de Castro Pereira - Alexandre de Pádua Carrieri

demonstrando o perfil de uma empresa enxuta, não somente da filial mas da própria holding, tanto para os empregados como para a sociedade, produziram-se novas significações culturais. A desterritorialização, somada à mudança de nome e de logotipo, buscaria promover duas estratégias: a primeira, provocar um desenraizamento real e simbólico dos espaços que lembrariam a outrora Telemig - o prédio-sede, a imagem da empresa e seu nome; a segunda, tentar fazer com que a nova organização fosse capaz de promover a reterritorialização; portanto, que aparecesse como um novo "espaço particular da experiência humana", um "lugar privilegiado de enraizamento" (Chanlat, 1992, p. 30-31), onde novas significações para as carreiras e conquistas pessoais dos atores poderiam ser construídas (Rodrigues, 1997).

Aos poucos, com o fortalecimento da matriz da Telemar, a ex-Telemig transforma-se em filial ocupada, principalmente, com os serviços de manutenção e vendas. Hoje a maioria dos andares do prédio, antes sede da empresa, está quase toda alugada, restando alguns andares (de três a quatro) ainda para a Telemar. Além disso, os outros prédios de que a empresa dispunha estariam sendo alugados. Segundo alguns empregados, "a Telemar é uma grande imobiliária se o negócio de telefonia não der certo, os acionistas podem viver de aluguel dos inúmeros imóveis que são da empresa" (técnico 66).

É interessante pensar, no conjunto organizacional, quantos prédios foram construídos para estender seu poder sobre novos territórios, no sentido de que havia a necessidade tecnológica de construir prédios para estender toda a malha telefônica. Todavia, as transformações continuavam. Em 2002,

Caíram todas as grandes divisórias, agora somente meia divisória. Aumentando o controle, pois todos se vigiam, até eu mesmo vigio o meu gerente (técnico 70)

Aumentou o barulho. Aumentou demais o barulho.(técnico 83)

É interessante, o espaço está sendo usado diferente. Veja, onde antes trabalhavam oito, hoje está com quarenta pessoas, todas em baias. São pessoas que não se conhecem, que hoje estão aqui, amanhã lá. Eu mesmo perdi quase todos meus colegas. Eles saíram ou foram para as prestadoras de serviços contratadas. (técnico 36)

Sabe, existe um trem diferente. É assim, olha, eles desativam certo setor, demitem muitos. Os que restaram são juntados com outros, em lugares que antes trabalhavam oito e hoje cabe uns trinta. Eles têm feito isso, muda o setor de prédio, de andar. Reduzem as pessoas, juntam com outras. Eu não conheço mais quem trabalha comigo (técnico 92)

Observa-se que há vários movimentos de ocupação e desocupação dos espaços simbólicos ainda sendo configurados na Telemar-Minas. Segundo os fragmentos discursivos acima se pode evidenciar que os espaços físicos reais da empresa estão diminuindo; contudo, se aumenta a lotação dos espaços restantes; onde antes caberiam algumas pessoas hoje, devido às novas estruturas para escritórios, podem ser colocadas de trinta a quarenta pessoas em um mesmo espaço. Segundo Fischer (1994) os espaços organizacionais são, freqüentemente, pensados no sentido da monofuncionalidade, de uma só função em um só lugar. Além disso, revelam sempre a estrutura de vigilância, de controle da empresa. $\mathrm{Na}$ Telemar-Minas, todos estão se vigiando, inclusive vigiando seu próprio gerente. Afinal, com trinta a quarenta pessoas trabalhando juntas, com meias divisórias separando-as, ver e escutar os outros é uma constante. Ainda para esse autor, esse tipo de organização do espaço é grande fonte de estresse; o que foi idealizado para aumento de controle e de produtividade é antes de tudo fonte de possíveis doenças, 
FÓRUM - GESTÃO NO BRASIL: ENFOCANDO PROCESSOS E RELACIONAMENTOS - MOVIMENTOS DE DESTERRITORIALIZAÇÃO E RETERRITORILIZAÇÃO NA TRANSFORMAÇÃO DAS ORGANIZAÇÕES Denise de Castro Pereira - Alexandre de Pádua Carrieri

pois ao indivíduo nega-se um espaço de recolhimento. Ele, o indivíduo, suas ações e falas são da coletividade, da empresa.

Outro movimento que se pode retirar dos fragmentos discursivos acima mostrados é a redução da mãode-obra. Muda-se determinado departamento de lugar, até mesmo de prédio, demitem-se funcionários e terceirizam-se serviços, transferidos para outros prédios, outra cidade onde se localiza a nova matriz, outros espaços com várias outras pessoas. Esse movimento talvez seja, para os funcionários efetivos da empresa, o pior, pois, como alguns deles disseram, não se conhecem mais as pessoas que estão juntas. A identidade grupal, que fazia as pessoas se reconhecerem trabalhando todas para a mesma empresa, aos poucos desaparece. O espaço de enraizamento de uma identidade grupal está cada vez menor na Telemar-Minas. Não se constroem laços de identificação com os colegas ou com seu espaço de trabalho. A qualquer momento o departamento pode ser extinto e o trabalhador ser demitido ou, se ainda for importante para a empresa, ser terceirizado. A empresa como um lugar especial, um território de identificação, desaparece. A empresa aos poucos busca submeter os indivíduos a uma lógica abstrata de lucro e expansão, não mais de relacionamentos e da construção de suas raízes sociais.

À guisa de síntese, pode se resgatar a trajetória histórica da organização para se compreenderem as transformações dos espaços simbólicos. Quando a Telemig se tornou parte da Telebrás, em 1973, ela incorporou outras 100 companhias no estado de Minas Gerais. Seu primeiro plano estratégico envolveu a extensão dos serviços ao interior do estado, integrando inicialmente mais de duzentas cidades sem conexões telefônicas e as companhias adquiridas em uma única holding. A identidade da Telemig foi construída em torno da missão de fornecer serviços de telecomunicações para todas as partes do estado, até mesmo as mais remotas. Durante o período de 1990 até 1995, quando teve início o processo de desterritorialização aqui estudado, observaram-se inúmeras mudanças significativas que contribuíram para a modificação da identidade da empresa no sentido da provisão de serviços, isto é, na mudança de uma empresa de engenharia para uma companhia de serviços. Na fase denominada pré-privatização, que vai de julho de 1995 até julho de 1998, assume uma nova diretoria indicada pelos governos federal e estadual. Essa nova diretoria busca implementar e aprofundar algumas transformações para tornar a Telemig mais rentável e, portanto, mais interessante para possíveis novos proprietários. Usa-se a metáfora do "terreno arado" (colhida na entrevista com um diretor) e busca-se aprofundar e institucionalizar as mudanças, isto é, definitivamente transformar a Telemig em uma empresa de negócios de telecomunicações. Por fim, quando em junho de 1998 ocorreu a privatização, a companhia teve que aprender novas formas de relacionar-se no mercado e com seus funcionários; o foco no cliente ficou mais intenso mesmo antes de privatização. Após julho de 1998, a Telemig transformava-se em Telemar. Aos poucos se pode ver que a organização ganhou espaço de ação como pertencente a uma empresa chamada Telemar, mas perdeu seu espaço de poder decidir sobre seu território, onde foi construída: Minas Gerais. Seus espaços físicos e simbólicos podem ser vistos não mais como territórios autônomos (ou são territórios perdidos!), pois ainda não demonstram conseguir promover a identificação entre as pessoas e a organização.

Deve-se ressaltar que, como elaborado por Santos $(1987,1996)$, a apropriação do espaço implica uma nova lógica em que o conteúdo simbólico, onde se inclui o espaço físico, é dado por quem impôs ou propôs a mudança na organização. Desse modo, os estudos sobre espaços deveriam possibilitar evidenciar as participações territoriais tradicionais que se defrontam com novas lógicas de ocupação, de gestão, por sua vez sustentadas por modelos considerados "modernos", trazendo novas e velhas subjetivações à visão de mundo e à visão organizacional dominada. 
FÓRUM - GESTÃO NO BRASIL: ENFOCANDO PROCESSOS E RELACIONAMENTOS - MOVIMENTOS DE DESTERRITORIALIZAÇÃO E RETERRITORILIZAÇÃO NA TRANSFORMAÇÃO DAS ORGANIZAÇÕES Denise de Castro Pereira - Alexandre de Pádua Carrieri

A concentração vertical e horizontal de um território, de uma organização, pode ser vista como uma forma micro de globalização, isto é, as empresas acabam concentrando-se em determinados espaços produtivos, geográficos, especializando a produção e concentrando as decisões em um lugar só (Benko, 1996). No caso da Telemar-Minas, a primeira fase, do começo dos anos 1990, começou a mudar a identidade da empresa. Ela deveria abrir-se para o mundo externo, atender aos clientes, evidenciando que o que se denomina mercado de consumidores estava ganhando cada vez mais supremacia frente ao público, ao social e, como apontam Degagné e Goh (1995), enfatizando que a privatização de uma empresa estatal é, antes de tudo, uma mudança ética. Quando a empresa é entregue ao setor privado, servir à sociedade, como comunidade de usuários públicos, deixa de ser um de seus objetivos centrais, passando a conquista do mercado e o lucro dos acionistas a se constituírem os seus novos objetivos.

\section{CONSIDERAÇÕES FINAIS}

Este estudo procurou localizar convergências, tangências e complementaridades com a gestão e a ocupação simbólica do espaço e do território. De certo modo, ao tema do espaço simbólico, da territorialidade e da desterritorialização se aproximaram conceitos como organizações, práticas, identid ade, significações culturais e, principalmente, relações de poder. Do mesmo modo, vale lembrar que os espaços simbólicos, como o território, são ambíguos e relacionais, permitindo em seu estudo revelar traços culturais e outros aspectos importantes no contexto das organizações. Para a gerência é importante compreender e administrar adequadamente as transformações na organização, pois a existência de diferentes tipos de territórios afeta as interações humanas.

O território pode ser estudado como a representação do espaço organizacional, social, marcado pela história dos atores sociais em relação à organização. Nele estariam enraizados os processos de identificação, de inscrição da história pessoal na organização, e ele funcionaria como sistema de referência. A compreensão da organização como espaço de ocupação simbólica supõe uma abordagem territorial que requer o mapeamento das estruturas e dos fluxos de atividades de produção, informação e, sobretudo, relacionamentos.

O conceito de territorialidade se apresenta como um significativo recurso teórico para uma análise organizacional por que permite a compreensão das articulações entre os diversos atores. Ao se estudar a territorialidade podem-se contemplar as diversas representações construídas nos conflitos e nas alianças entre grupos e indivíduos, na aceitação e nas traduções dos discursos dominantes. A identificação das dinâmicas de desterritorialização e reterritorialização pode incrementar a compreensão das complexas relações de poder que estruturariam as práticas e os processos produtivos. A importância de uma perspectiva crítica desses temas se torna mais evidente em situações de transição porque suas manifestações emergem carregadas de conteúdos novos, percebidos pelos indivíduos envolvidos nos processos de mudanças organizacionais como forma de perda simbólica.

O estudo da ocupação dos espaços simbólicos e físicos - até então bastante relegado nos estudos organizacionais brasileiros - pode trazer contribuições para os estudos de gestão, evidenciando os relacionamentos e processos organizacionais que advêm de uma construção sócio-histórica. Ao se trabalharem os impactos da desterritorialização e reterritorialização dos espaços, podem-se aferir 
FÓRUM - GESTÃO NO BRASIL: ENFOCANDO PROCESSOS E RELACIONAMENTOS - MOVIMENTOS DE

DESTERRITORIALIZAÇÃO E RETERRITORILIZAÇÃO NA TRANSFORMAÇÃO DAS ORGANIZAÇÕES Denise de Castro Pereira - Alexandre de Pádua Carrieri

possíveis conseqüências para os indivíduos e, efetivamente, para o desempenho organizacional, no sentido de esvaziar os espaços corporativos de seu conteúdo relacional e particular, que promoveriam uma identificação entre os indivíduos e as organizações. No caso brasileiro, esse tema se reveste de grande importância, pois permite uma releitura das estratégias organizacionais, possibilitando evidenciar diversas experiências por meio das quais se desvelam processos de mudanças nas formulações das políticas organizacionais e tecnologias gerenciais, muitas vezes importadas, mas que se concretizam por meio de bricolagens em ambientes marcados pela diversidade cultural brasileira.

\section{REFERÊNCIAS BIBLIOGRÁFICAS}

ALCADIPANI, R.; ALMEIDA, A. O. O feitiço incluiu o feiticeiro: uma análise sobre a implementação de um escritório aberto. In: ENCONTRO ANUAL DA ASSOCIAÇÃO NACIONAL DOS PROGRAMAS DE PÓS-GRADUAÇÃO EM ADMINISTRAÇÃO. 24., 2003, Florianópolis. Anais. Florianópolis: ANPAD, 2000.

BENKO, G. Organização econômica do território: algumas reflexões sobre a evolução no século XX. In: SANTOS, M.; SOUZA, M. A.; SILVEIRA, M. L. (Orgs.). Território : globalização e fragmentação. São Paulo: Hucitec/Anpur, 1996.

BOURDIEU, P. O poder simbólico. Lisboa: Difel/Bertrand do Brasil, 1989.

BUTTIMER, A. O espaço social numa perspectiva interdisciplinar. In: SANTOS, M.; SOUZA, M. A. A. O espaço interdisciplinar. São Paulo: Nobel, 1986.

CERTEAU, M. A invenção do cotidiano. Petrópolis: Vozes. 1994.

CHANLAT, J. F. Por uma antropologia da condição humana nas organizações. In: CHANLAT, J. F. (Org.). O indivíduo na organização: dimensões esquecidas, v. 1, São Paulo: Atlas, 1992. p. 21-45.

CLEGG, C.; KORNBERG, M.; DOBERS, P. Space and Organization. Disponível em <http://www.egos.cbs.dk>. Acessado em: 20 abril, 2003.

CORRÊA, R. L. Territorialidade e corporação: um exemplo. In: SANTOS, M.; SOUZA, M. A. A.; SILVEIRA, M. L. (Orgs.). Território: globalização e fragmentação. São Paulo: Hucitec/Anpur, 1996.

DEGAGNÉ, A. J; GOH, S. C. 1995. Transforming the culture of a public sector organization. In: PROKOPENKO, J. (Ed.). Management for Privatization. Geneva: International Labour Office, 1995. p. $164-184$.

FARIA, A. A. M. Interdiscurso, intradiscurso e leitura. O caso de Germinal. In: Mari, H.; Machado, I. L.; Mello, R. (Orgs.). Análise do discurso: fundamentos e práticas. Belo Horizonte: Núcleo de Análise do Discurso, Fale/UFMG, 2001 . p. 241-287. 
FÓRUM - GESTÃO NO BRASIL: ENFOCANDO PROCESSOS E RELACIONAMENTOS - MOVIMENTOS DE DESTERRITORIALIZAÇÃO E RETERRITORILIZAÇÃO NA TRANSFORMAÇÃO DAS ORGANIZAÇÕES Denise de Castro Pereira - Alexandre de Pádua Carrieri

FARIA, A. A.; LINHARES, P. de T. F. S. O preço da passagem no discurso de uma empresa de ônibus. Cadernos de Pesquisa, Belo Horizonte, n. 10, p. 32- 38, 1993.

FERNANDES, B. H. R.; FONSECA, V. S.; MACHADO-DA-SILVA, C. L. Cognição e institucionalização na dinâmica da mudança em organizações. In: CUNHA, Miguel P.; RODRIGUES, Suzana Braga (Orgs.). Estudos organizacionais: novas perspectivas na administração de empresas: uma coletânea luso-brasileira. São Paulo: Iglu, 2000. p. 123-150.

FISCHER, G-N. Espaço, identidade e organização. In: CHANLAT, J. F. (Coord.). $O$ indivíduo a organização: dimensões esquecidas. v. 2. São Paulo: Atlas, 1994.

GUATTARI, F. As três ecologias. Campinas: Papirus, 1993.

HAESBAERT, R. Des-territorialização e identidade: a rede "gaúcha" no Nordeste. Niterói: EDUFF, 1997.

HARVEY, D. A condição pós-moderna. São Paulo: Loyola, 1992.

MAC-ALLISTER, M. Organização-cidade: uma contribuição para a ampliação do conceito de cidade no campo dos estudos organizacionais. (Tese de doutorado). Salvador: UFBA, 2001.

MAC-ALLISTER, M. Emergência do espaço organizacional para a gestão social. In: IX Colóquio Internacional sobre Poder Local, 2003, Salvador. Anais do IX Colóquio Internacional sobre Poder Local. Salvador: Escola de Administração - EAUFBA, 2003

MUMBY, D. K; CLAIR R. P. Organizational discourse. In: VAN DIJK, I (Org.). Discourse as Social Interaction. London: Sage, 1997. p. 181-205.

PAGÈS, M.; BONETTI, M.; GAULEJAC, V.; DESCENDRE, D. O poder das organizações: a dominação das multinacionais sobre os indivíduos. São Paulo: Atlas, 1987.

RAFFESTIN, C. Por uma geografia do poder. São Paulo: Ática, 1993.

RODRIGUES, S. B. Cultura corporativa e identidade: desinstitucionalização em empresa de telecomunicações brasileira. Revista de Administração Contemporânea, Curitiba, v. 1, n. 2, p. 45-72, 1997.

RODRIGUES, S. B.; COLLINSON, D. L. Having fun? Humor as resistence in Brazil. Organization Studies, Berlin, v. 16, n. 5, p. 739-768, 1995.

SANTOS, M. O espaço do cidadão. São Paulo: Nobel, 1987.

SANTOS, M. O retorno do território. In: SANTOS, M.; SOUZA, M. A. A.; SILVEIRA, M. L. (Orgs.). Território: globalização e fragmentação. São Paulo: Hucitec/Anpur, 1996.

SPINK, P. O lugar do lugar na análise organizacional. In: ENCONTRO ANUAL DE ESTUDOS ORGANIZACIONAIS, 1., 2001, Curitiba. Anais. Curitiba: ANPAD, 2001. 
FÓRUM - GESTÃO NO BRASIL: ENFOCANDO PROCESSOS E RELACIONAMENTOS - MOVIMENTOS DE DESTERRITORIALIZAÇÃO E RETERRITORILIZAÇÃO NA TRANSFORMAÇÃO DAS ORGANIZAÇÕES Denise de Castro Pereira - Alexandre de Pádua Carrieri

VIEIRA, E. F.; VIEIRA, M. M. F. Geoestratégia dos espaços econômicos: o paradigma espaço-tempo na gestão de territórios globais. In: FISCHER, T. (Org.) Gestão do desenvolvimento e dos poderes locais: marcos teóricos e avaliação. Salvador: Casa da Qualidade, 2002. p. 45-60.

Artigo recebido em 16.07.2003. Aprovado em 20.05.2004.

\section{Denise de Castro Pereira}

Professora da PUC-MG. Doutoranda em sociologia pela UFRJ.

Interesses de pesquisa nas áreas de organizações, empresa e sociedade e sociologia da empresa.

E-mail: dpereira@pucminas.br

Endereço: Rua Passagem, 111, Bairro Serra, Belo Horizonte - MG, 30220-390.

\section{Alexandre de Pádua Carrieri}

Professor do Cepead/UFMG. Doutor pelo Cepead/UFMG.

Interesses de Pesquisa nas áreas de organizações e simbolismos.

E-mail: alexandre@cepead.face.ufmg.br

Endereço: Rua Cristina, 303, ap. 02, Bairro Sion, Belo Horizonte - MG, 30310-800. 